\title{
A New Look at the Three World Classification*
}

\section{Dudley Seers}

A 'Three world' classification of nations has been in use for the third quarter of this century in two distinct respects. First, the structures of international organizations, (e.g. the committees of UNCTAD ${ }^{1}$ ) have been based on the three classes of 'centrally planned', 'developed' and 'less developed' or 'developing' countries, in the odiously euphemistic language of the United Nations (the last group has also been known as the 'Third World'). Secondly, this classification has helped to shape the way in which we perceive and interpret international events.

I am going to look briefly at the basis and implications of this division, then at the way in which it has been eroded by political and economic trends in the last two decades, and conclude by suggesting a classification which looks more appropriate for the remainder of the century, with some notes on its implications for national policy.

The conventional classification has rested on two criteria-whether a country is or is not 'Communist', and secondly on its level of income (and industrialisation). As a system its acceptability has depended partly on the fact that it is convenient to the parties concerned. Governments of 'developing' countries use it as a means of pressure on the 'developed' to obtain commitments such as the generalisation of preferences and aid targets, etc. It is also convenient to the Communist bloc that the main division encouraged the former colonies to address their demands to the former metropolitan countries. While the government of 'developed' countries found these demands irksome, they accepted, for various reasons, that they did have some interest in helping the 'developing' countries to become 'developed', in the foreseeable future, without passing through a Communist phase.

This international classification was consistent with the Harrod-Domar national growth model. It implied that a 'developing' country could, by planning to raise its per capita national income, achieve a more prestigious place in the world

* Based on seminars given at the Universities of Harvard and Puerto Rico, and a contribution to a consultative meeting of the United Nations University in Tokyo.

1 There are in fact four country committees in UNCTAD, since separate ones operate for Latin America and the Afro-Asia group. However, for many purposes these last meet jointly. order and greater economic independence. It led to the Third World demands for capital, in UNCTAD I, II and III, which was believed to be a necessary, even almost sufficient, condition for achieving this growth.

A common belief in the 1950 s was that shelves were full of the necessary technologies and the Third World could simply help themselves. The 'developed' countries had solved their economic and social problems and those of the Third World could do the same if they followed in the former's footsteps. Their task was easier than that of countries which were industrialising in the 19th century. If they invested enough and still did not grow, this must be due to 'obstacles'-religions, traditional customs, family systems, linguistic barriers, excessive fertility, etc., etc., which hindered the operation of the various factor and product markets.

The strategy for 'developing' countries, expressed in 'development' plans, and Development Decade documents, was therefore to grow by modernisation. Before long, hopefully, a modern standard of living would be within everyone's reach. The task of international organizations such as UNCTAD was primarily to arrange the transfer of resources to facilitate this; it was expressed in targets for growth rates and for transfers of aid and private capital, and resolutions about tariff preferences, commodity prices, etc. The delegations of 'developed' countries usually supported these resolutions reluctantly and with little intention of implementation.

\section{The collapse of the model}

In suggesting how this set of ideas, which amounted to a model of world development, was undermined, I have to generalise even more wildly. Perhaps the most significant development was that countries with sustained fast economic growth, as high as 3-4 per cent in per capita terms, did not by any means experience reductions in unemployment, inequality or poverty. Nor did they become economically more independent.

Import substituting industrialization turned out to reinforce imported styles of consumption enjoyed by small minorities and to create new sorts of dependence on capital, technology and intermediate products from abroad. It also usually led to some neglect of the agricultural sector and therefore dependence on imported foodstuffs, 
especially wheat; many countries which had been traditionally cereal exporters became importers.

While these economic trends were undermining the growth-centered ideological counterpart of the three-world system, it was also being made obsolete by other developments: first, a degree of 'convergence' between the communist and noncommunist worlds with some of the former (such as Hungary) relying much more on market forces, while state intervention and nationalisation has spread in the latter. In any case China and one or two other Communist countries had broken their political alignment with the Soviet Union and increasingly diverged in political behaviour.

There has also been a growing fuzziness in the boundary between the 'developed' and 'developing' countries. Western Europe has been developing into a 'developing area', showing characteristic chronic payment difficulties, chronic unemployment and chronic inflation. More to the point, Western Europe has itself increasingly been importing technology and capital via transnational companies. The impact of the word 'developed' and its power to inspire emulation was weakened by none of the 'developed' any longer seeing themselves as paradigms. Nor do they have much capital to spare after meeting the politically pressing demands of their own populations for ever higher consumption levels.

This model of world development was further weakened by the combined oil and food crises of the last three years. In the first place, this exposed the vulnerability of growth strategies based on highly-mechanised industrialisation. Secondly, it showed that there were other ways of obtaining resources than waiting for the 'developed' countries to provide capital. Thirdly, it cast a considerable question mark against the possibility of the whole world population reaching a modern standard within the next couple of generations or indeed ever. The world suddenly became a much less benign place.

The question also now rises: how does one classify Kuwait, which has the highest per capita income in the world? If we describe Kuwait as more 'developed' than the United States this intuitively seems absurd. Although it exports a great deal of one saleable commodity, it is also weak in several important respects. Its citizens are accustomed to extremely comfortable consumption standards but it has to import almost everything. Kuwait is a town in the desert and produces practically no food except vegetables. It has to import technology for all sectors, even the petroleum industry. It has nationalized the physical assets of the petroleum companies but it cannot nationalize their main assets, production technology and access to world markets. It is still dependent on the flow of expertise from abroad, even to extract its main economic asset, oil. And it is also a country with too small a population to defend itself (and the Gulf is a politically unstable area). It also lacks national unity: about half the resident population are migrants from Palestine, India, Iran, Iraq, etc., who have taken jobs which could not be filled by citizens.

\section{The dimensions of dependence}

A country is economically dependent on the rest of the world to the degree that its production structure does not match its consumption structure. It is a matter of consumption styles as well as whether the country concerned can produce locally the necessary inputs to sustain them.

To assess the nature and degree of a country's dependence, simulate a situation in which it is cut off from the outside world and therefore from its normal sources of supply of oil, food and technology and ask what the consequences would be of being cut off from them and how tolerable these would be. It is not necessary for this to happen or even for it to be a real possibility. The potential consequences of autarchic policies put a brake on its freedom of action. (In a primitive community, such as a mining camp, a man's relative physical strength does not have to be tested in a fight for him to dominate other males.) There are many economic inputs which it would be painful to do without-metal ores, textile fibres, etc. But clearly the most important are energy and food, which means basically petroleum and cereals.

Dependence is not only an economic concept. Clearly the power a government exercises depends also on the military force at its disposal. This too is related to technology and especially the capacity to produce its own weapons.

It is also related to population size, because this affects the numbers in the armed forces, and (more important and more directly) the numbers available to be mobilised in time of war. Size of population is also relevant in other ways. At a given level of income, it determines the size of the market, which is in turn clearly related to the structure of production, especially the size of the sector producing capital equipment. It also affects the number of research and development staff. This in turn determines the level of technology and the capacity to select imported techniques appropriate to national needs. ${ }^{2}$

2 Of course to say that a large population is an asset to a country is not to imply that population growth strengthens it. 
A country's size can also measured in terms of area. This may also be an asset. A large country is (as Russia has often shown) more capable of absorbing and defeating invading armies. Since oil and other natural resources are scattered more or less randomly, the larger a country is (including its territorial waters) the more likely it is to have petroleum and metals, and also areas suitable for growing cereals (though much, of course, depends on climate, soil and technique as well). However it is not necessarily helpful to a country to have a large area, even a large arable area, if they have to support a large population (India being the classic case). Still for a large population to have a limited arable area (as Japan has) is a definite weakness.

Another type of dependence is political-military alliances, political organisations, etc. Another again is cultural-importing magazines, TV programmes, news agency material, etc., adapting foreign fashions in everything from religions to economic models, languages and styles of clothing. ${ }^{3}$ Political and cultural autonomy depend on the degree of politico-cultural unity, reflecting class differences and also ethnic and linguistic heterogeneity, which have their roots in national history, especially in the colonial period, when settlers and immigrant labour often arrived. ${ }^{4}$ The key question here is the extent to which a government can appeal successfully to patriotism to justify sacrifices.

If I only list these influences it is not because they are unimportant, but because I want to propose a manageable system of classification of countries in a limited space. I could, however, go a step further and suggest that while political and (especially) cultural determinants of a government's room to manoeuvre, are important, there is a greater long-term reality to a country's population and resource base.

\section{A dependency classification}

The table indicates for a number of countries the degree of self-sufficiency in technology, cereals, and oil. The fourth column shows size of population. ${ }^{5}$ Certain features stand out from the table. In the first place, the United States, the Soviet Union and China, having large populations, are militarily far more powerful than other countries

3 Another factor determining in some degree political and cultural dependence is location, especially in relation to countries which are more powerful in these respects.

4 Countries with large populations are usually far from 4 Countries with large populations are usually far from diversity of ethnic and linguistic groups may be a source of strength, provided no single one is partially dominant. Ethnic differences may be more important in small bi-racial countries such as Malaysia and Singapore.

5 Area is not shown; population is a proxy for it (though a weak one). and none of them entirely lack any of the three key resources. They are each net importers of just one of them-this is true only of these countries. They would be the best able to withstand a breakdown of trade with the rest of the world (as indeed they have in various ways demonstrated).

\begin{tabular}{lllll} 
The Assets and Liabilities & \multicolumn{4}{c}{ of } \\
& Technology & Cereals & Oil & Size \\
USA & $* * *$ & $* * *$ & $*$ & $* * *$ \\
Soviet Union & $* *$ & $*$ & $* * *$ & $* * *$ \\
China & $*$ & $* *$ & $* * 1$ & $* * * 2$ \\
\hline Japan & $* *$ & $*$ & 0 & $* * *$ \\
West Germany & $* *$ & $*$ & 0 & $* *$ \\
East Germany & $* *$ & $*$ & 0 & $* *$ \\
\hline Kuwait & 0 & 0 & $* * *$ & 0 \\
Iran & 0 & $*$ & $* * *$ & $* *$ \\
\hline Brazil & $*$ & $*$ & $*$ & $* * *$ \\
Cuba & $*$ & $*$ & 0 & $* * *$ \\
Costa Rica & 0 & $*$ & 0 & $*$ \\
\hline
\end{tabular}

1 Apparently turning into an export surplus.

2 Considerably larger than the others $($ c. $700 \mathrm{~m}$.)

First three columns (resources)

$\star \star \star$ Net exporter

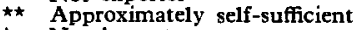

* Net importer

o Virtually zero capacity.

Fourth column (population)

$\star \star \star>100 \mathrm{~m}$.

$\star \star \quad 10-100 \mathrm{~m}$

$\star * 1-10 \mathrm{~m}$.

It would, however, be wrong to call them 'independent'. Although they each have only one weakness, it is serious. For the United States, it is oil (which might in the long-term be overcome by the development of shale coal and nuclear energy): the US is also a net inporter of iron ore and other important metals. Cereals are the Achilles heel of the Soviet Union (and to cure this would apparently require a big and difficult reorganisation of the rural economy). The Chinese deficiency is in technology including nuclear arms: this can be made up more easily, suggesting their possible emergence as the most independent country in a few decades, especially since consumer aspirations can presumably be more effectively restrained in China than elsewhere, certainly than in the United States.

All three would find autarchy uncomfortable. Moreover they are dependent in other senses; their military security requires neighbours which are at least neutral. Some countries are currently termed the 'least developed': let us call these three the 'least dependent', to reflect their partial but limited dependence.

Japan is often counted as a 'super power' and certainly its per capita income is far higher than that of China. It has a big population and exports 
technology (and thus capital equipment ${ }^{6}$ ) as well as importing it. It has another great asset, which does not appear on the table: a population more homogeneous, ethnically and linguistically, than that of almost any other country. Its social class differences are severe and (unlike the three 'least dependent' countries) a general strike against the government within the next few years is not unthinkable. But a common culture is deeply rooted in Japanese history and it could be argued that in a politico-economic crisis its population would show considerable cohesion. Still, if Japan were cut off from the outside world it would crash to destruction: imported oil is needed to enable the population to keep warm, to communicate, to move from one place to another (even to open doors of buildings and raise people to their apartments) and to produce and distribute other necessities. Life styles would have to be drastically changed if food imports were eliminated.

The structural pattern of West Germany is strikingly similar, and with a few variations this could be broadly taken as representative of the countries of Western Europe too. ${ }^{7}$ They buy technology (and also arms and equipment) from multinational corporations based in the United States, but also export these to other West European countries and the rest of the world, via multinational private or state corporations based in Western Europe. They are mostly partially dependent on imported cereals, and highly dependent on imported oil. ${ }^{8}$

To call them a separate group does not imply that they will always co-operate in policy matters. They do indeed have a collective interest in exerting their combined bargaining power, vis-à-vis the United States, oil exporters, etc. But, as always, situations may develop which tempt individual members of cartels to break away and negotiate bilateral contracts. ${ }^{9}$

This approach to international analysis seems more useful than the conventional one in explaining the growing divergence of behaviour among the governments of 'developed' countries, between the United States and the others. The latter are hardly even consulted any more on major US initiatives. ${ }^{10}$ The emergence of a sellers' market in

\footnotetext{
6 Because of restrictions imposed after the war, Japan is not a manufacturer of majcr military equipment such as warplanes.

7 West Germany in one respect is not typical-it is highly dependent on immigrant werkers.

8 E.E.C. would depend heavily on oil if it were a single country. Of course it would have a large total population, but could not be considered as in the same 'least dependent' class as the USA, the Soviet Uni-n or China.

9 This is especially likely to be true of Britain and Norway because of their potential export capacity in oil.

$10 \mathrm{It}$ is true that there has also bsen an additional reason, the greater weight of pro-Israel political lobbies in the United States than elsewhere, but this hardly appears sufficient to justify the go-it-alone policy of the US government.
}

cereals, and the increasing importance of technology, especially in the extraction of oil and metals (including exploration offshore and by satellite), means that United States interests differ more profoundly from those of Western Europe than previously, and that its bargaining strength is much greater. The US government is clearly determined to open new channels of negotiation outside UNCTAD, to weaken OPEC and to reach an arms agreement with the Soviet Union.

For some purposes it seems better to consider Japan and the countries of Western Europe as a separate class, which one might call 'semidependent'. They are not unanimous in defending multinational corporations when these are under attack at UNCTAD (since they too are often subject to heavy economic and political pressures from US corporations) and they also have less bargaining strength vis-à-vis countries exporting primary products.

Analogous developments have occurred among 'Communist' countries. Differences between resource patterns in Eastern European countries on the one hand and in the Soviet Union on the other have become increasingly important. So for many purposes it may be more useful to class the latter as 'semi-dependent' too. Apart from the convergence in forms of economic organisation, there is therefore an additional reason to suspect a growing commonality of interest between Western and Eastern Europe.

Another class of countries are also 'semi-dependent', but in a different sense-the petroleum exporters. The bigger members of OPEC, like Iran, differ from the smaller ones, such as Kuwait, in several important respects, notably the existence of an agricultural hinterland and a much larger population base. But they also all have much in common. In complete contrast to Europe, they have oil to trade for technology, arms and equipment, and for manufactured imports to meet very high consumer expectations. While the exportable surplus of oil is only temporary, from an historical perspective, for several decades many of them will have interests different from those of other groups, including the rest of the "Third World'.11

I have shown only a few non-OPEC 'developing' countries in the table. Nearly all countries in Africa, Asia and Latin America depend on imported cereals and oil, and on imported technology. To buy these, they offer less essential commodities such as coffee, tea, bananas, cocoa,

11 In 1974, they were portrayed by some as almost another world power (eg. in the doctrine of 'polycentricity'). However, the very euphoria cf that time has led to such \& massive waste of resources that it is no longer even conceivable to depict them in this way. 
sugar and cotton. (Some also have tourist facilities.) They can therefore truly be termed 'dependent' countries. This dependence is manifested in a basically passive attitude to foreign investment. 12

Since they also share with OPEC members a chronic reliance on imported technology, equipment and arms, there is an economic rationale in the continuance of the 'Third World' as an entity, in support of the New International Economic Order. ${ }^{13}$ This has been reinforced by the use of part of oil revenue as aid. The political basis is a persisting determination to revenge humiliations suffered in the colonial period and to achieve respectable world status.

The communist-capitalist split also continues to have organisational and ideological reality, ${ }^{14}$ so the 'Three World' classification still has some life left But one must expect an acceleration in the fragmentation of the three worlds and the growing importance of geographical and social factors. This will become more evident when the recession is succeeded by a new phase of rapid expansion, raising world income well above the $1973 / 4$ peak and revealing crucial supply difficulties again. Indeed another world cereal shortage has apparently emerged already, before the recession is over. In the 1980 s and 90 s, population pressure will allow little relief from resource problems.

\section{Policies for a less benign world}

Finally, a few words on the national development policies that would be compatible with this approach. First, there are no fundamental differences in the strategies appropriate to the governments of 'centrally planned', 'developed' and 'developing' countries. The crucial task for every government is to develop technical expertise and to control consumer aspirations. For all of them, though in different ways, what were thought of as 'obstacles' to development when this was synonymous with economic growth - nationalism, separate languages, traditional customs, etc.-

12 Typically the capital of a dependent country is beseiged by visiting business men with investment projects.

13 The NIEO is however ambivalent, as perhaps is to be expected in a period of rapid transition. On the one hand it stresses the rights to national ownership of natural resources and to form sellers' cartels; on the other, it is stil concerned with the continuation of inflows of capital and technology. One might put it that underlying a cry of "rape" is a low murmur: "But for God's sake don't stop yet".

14 The dependence of many governments is not a general dependence on the outside world as a whole, but specifically towards one or two others, usually United States or the Soviet Union. An ideological division has been reinforced by links in trade and also culture. In fact the ideological distinction is becoming of decreasing relevance. If the Soviet Union were to become capitalist (or, for that matter, the United States experienced a communist revolution) it would not make a great deal of difference to the world structure: all governments must use their bargaining world structure: all governments must use their bargaining
power as best they can to protect the consumption standards of their own populations. appear rather as shields against modern consumption styles and technologies which cannot be afforded by more than a minority of the populations, and which increase dependence. Outside the 'least developed' countries, the universal need is for sufficient technical and administrative capacity to screen the importation of production and consumption techniques, and monitor those which have been allowed into the country.

It follows that a planning office should no longer be primarily concerned with growth targets or with projects, but with creating the cadres capable of evolving and implementing a development strategy expressed in targets for key resources and styles of consumption. Its second priority would be building up the information needed to back such a strategy, especially in negotiations with foreign firms and governments-information on the range of technologies available internationally, on the cost of different ways of obtaining them, etc.

In order to support these strategies, a development plan will also need to devote substantial resources to reinforcing nationalism - e.g., strengthening national and religious organisations; preserving and developing shrines and monuments, supporting traditional crafts, etc. Another requirement is adequate armed forces and a development plan needs to indicate their optimal size in relation to other safeguards of independence.

Measures to check the waste of key resources would in themselves do something to check social polarization. But in addition, many governments may well need more purposive policies to eliminate inequalities based on social classes, race or region, and acute poverty, if they are to achieve the national unity necessary to back national policies in technology and resource exploitation. ${ }^{15}$ This points to the need, on these grounds alone, for policies of redistributing property and income. Lowering the concentration of income would reduce demand for imported technology and oil (though possibly raising the demand for imported cereals).

Governments which lack the political basis for this may well face serious crises. ${ }^{16}$ It also points to the need for technology policies that reconcile the objectives of spreading employment and income with the fast development of key sectors.

There are implications for aid lobbies in the less dependent countries. In a world of slower

15 This is already the guiding philosophy of the development plans of Malaysia. Of course, in some synthetic countries, the region may be, especially for its inhabitants, the natural focus of loyalty and planning.

16 This reinforces in fact the need for introducing distributive targets, already felt in 1960 s because of the social distortions of purely growth-oriented strategies. 
economic growth there is less prospect than ever of liberal internationalism, based on feelings of guilt, being an effective force in the redistribution of world income. The primary function of lobbying governments before, e.g., UNCTAD is no longer an endless and essentially vain battle to shift a little more resources so as to raise marginally the growth rate of 'developing' countries. It is to stimulate delegations to find ways of reconciling the needs of countries with various resource patterns, so that international strategies and initiatives can be developed in key fields, especially energy and food.

In brief, recent developments have undermined the belief in an essentially benign world, in which nationalism was seen as an archaic but disappearing impediment to modernization and social change. It is now more obvious than ever that no 'international order' will survive unless it is based on an acceptance of realities, namely the basic interests of countries of all types. 